\title{
Surgical anatomy of the nasolacrimal duct on the lateral nasal wall as revealed by serial dissections
}

\author{
Ertugrul Tatlisumak $\cdot$ Asim Aslan • \\ Ayhan Cömert $\cdot$ Samet Ozlugedik . \\ Halil Ibrahim Acar · Ibrahim Tekdemir
}

Received: 4 February 2009/Accepted: 17 March 2009/Published online: 15 April 2009

(C) Japanese Association of Anatomists 2009

\begin{abstract}
The anatomy of the nasolacrimal duct (NLD) in relation with the lateral nasal wall was studied in 15 half-heads of human adult cadavers by serial photographs of the dissection of the lateral nasal wall. The aim of the study was to determine the intranasal anatomical relationships of the NLD with the lateral nasal wall for surgical reference during endoscopic dacryocystorhinostomy. Following removal of the nasal mucosa anterior to the uncinate process, the exposed bone was removed by drilling. The entire NLD was exposed intranasally. The relationships of the NLD with the maxillary sinus ostium and anterior nasal spine were determined, and the length of the NLD was measured. The morphology of the NLD opening was observed, and its distance from several landmarks were measured. There were three types of intranasal orifice: pin-point, triangular and slit-like. The NLD is located, on average, $24.6 \pm 3.56 \mathrm{~mm}$ posterior to the anterior nasal spine. The nearest distances between the opening of the NLD and the nasal floor and between the opening of the NLD and the most anterior attachment
\end{abstract}

E. Tatlisumak

Department of Anatomy, School of Medicine,

Celal Bayar University, Manisa, Turkey

A. Aslan ( $\square)$

Department of Otorhinolaryngology, School of Medicine, Celal Bayar University, Manisa, Turkey

e-mail: asimas98@yahoo.com

A. Cömert · H. I. Acar · I. Tekdemir

Department of Anatomy, School of Medicine,

Ankara University, Ankara, Turkey

S. Ozlugedik

First Otorhinolaryngology Clinic,

Numune Education and Research Hospital, Ankara, Turkey of the inferior nasal concha were $13.7 \pm 3.15$ and $14.3 \pm 2.05 \mathrm{~mm}$, respectively. The length of the NLD was $21.9 \pm 2.03 \mathrm{~mm}$ on average. The nearest distances between the NLD and the maxillary sinus ostium was $3.9 \pm 0.88 \mathrm{~mm}$. Cadaver dissections and the photographs of the fine dissections provide a more accurate description of the lateral nasal wall anatomy. These data provide valuable anatomical information to the surgeon performing endonasal dacryocystorhinostomy.

Keywords Anatomy - Eye - Lacrimal apparatus . Nasolacrimal duct $\cdot$ Sense organs

\section{Introduction}

The endoscopic technique is currently the most favored procedure for the surgical treatment of sinonasal pathologies. This technique allows direct visualization, evaluation and treatment of the intranasal abnormalities, three distinct advantages which make it preferable to external dacryocystorhinostomy for the surgical treatment of epiphora. In addition, the endoscopic technique obviates the need for a skin incision, which is an undesirable consequence of the external approach (Metson 1991; Weidenbecher et al. 1994; Sprekelsen and Barberan 1996; Unlu et al. 2000; Unlu et al. 2002). The nasolacrimal apparatus is intimately associated with the lateral nasal wall and may readily be approached using an endoscopic technique, which minimizes functional interference with the physiological action of the lacrimal apparatus.

Despite these favorable results compared with conventional surgical treatment, complications can still easily occur because the endoscope only allows monocular vision, which may cause the surgeon to become spatially 
disoriented, and a limited scope of the operative field. The success and safety of intranasal endoscopic surgery primarily depend on the surgeon' $s$ knowledge of intranasal anatomy, especially that of the lateral nasal wall. Although there have been a number of reports on the surgical anatomy of the nasolacrimal duct (NLD) in relation to the lateral nasal wall, these involve either drawings or computed tomography (CT) scans (McDonogh and Meiring 1989; Kurihashi et al. 1991; Rebeiz et al. 1992; Thanaviratananich et al. 1996; Groell et al. 1997; Unlu et al. 2000; Wormald et al. 2000). Current anatomical knowledge of this region is inadequate in terms of preparing the surgeons for intranasal interventions. Due to the possibility that such drawings are inconsistent and inaccurate, cadaver studies are still an invaluable approach by which surgeons can increase their knowledge and understanding of the anatomy of the area (Lucente and Schoenfeld 1990).

The aim of this study was to review of the anatomy of the nasolacrimal apparatus in relation to the lateral nasal wall by presenting photographs taken during the various steps of NLD dissection and to measure the distances of surgically important landmarks from relevant structures as a means for assisting the surgeon to grasp three-dimensional anatomy.

\section{Materials and methods}

The study was conducted on 15 half-heads of adult human cadavers (two female, 13 male), of which seven were the left side and eight were the right side. No information was available on the ages of the cadavers. All dissections were made under an operating microscope. The first step was to identify the orifice of the NLD in the inferior nasal meatus. To obtain a better exposure, a rectangular area (approx. $0.5 \times 1 \mathrm{~cm})$ of the inferior nasal concha, i.e. inferior turbinate (IT), was completely removed (Figs. 1, 2a, 3). The morphology of the orifice was noted. To have a better view, the anterior part of the middle nasal concha, i.e. middle turbinate (MT), was resected vertically up to its anterior attachment (Fig. 2b). Next, the mucosa on the lateral nasal wall was removed completely, starting from the level of the inferior nasal concha up to the anterior attachment of the middle nasal concha (Fig. 2c). The thin bone over the NLD orifice was removed, and the most inferior part of the NLD was observed (Fig. 2d). To see the relationship with the maxillary sinus ostium (MSO), i.e. maxillary sinus antrum and frontal recess and frontal sinus ostium, the uncinate process and anterior part of the MT were resected, leaving a small stump of MT for orientation (Fig. 2e). Bone removal was continued by drilling up to the anterior attachment of the MT, and the entire course of the NLD on the lateral nasal wall was obtained (Fig. 2f). The removal of mucosa and bone was continued superiorly to the

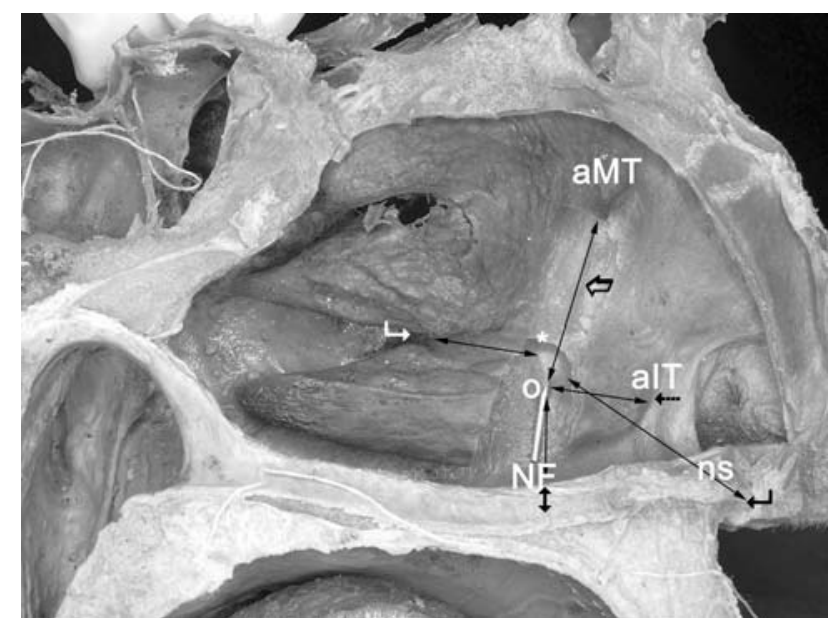

Fig. 1 Measurement points on the left lateral nasal wall. The pinpoint orifice ( $o$ ) is seen (probe). aMT Anterior attachment of middle turbinate, aIT anterior attachment of inferior turbinate (dashed black arrow), NF nasal floor (black vertical arrow), ns nasal spine (leftsided black arrow), big black arrow nasolacrimal duct, right-sided white arrow maxillary sinus ostium, asterisk superior attachment of inferior turbinate

anterior attachment of the MT to expose the nasolacrimal sac (NLS) (Fig. 2g).

The following parameters were measured (Fig. 1) and noted: (all measurements were made using a digital caliper and rounded off to the nearest millimeter):

- length of the NLD (from the transition area between the sac and duct up to the intranasal orifice);

- nearest distance from the NLD to the MSO;

- nearest distance from the NLD to the anterior nasal spine;

- nearest distance of the intranasal orifice of the NLD to the nasal floor;

- nearest distances of the intranasal orifice of the NLD to anterior attachment of the IT.

The SPSS ver. 10.0 program (SPSS, Chicago, IL) was used for statistics. Mean, standard deviation and the minimum and maximum values of all measurements were determined, and the values were rounded into values having two digits after the points.

\section{Results}

The intranasal orifice of the NLD is located at the roof of the inferior nasal meatus, just inferior to the superior attachment of the inferior nasal concha to the lateral nasal wall (Figs. 1, 2a, 3). Because of this position, it is difficult to observe the intranasal orifice of the NLD directly, even by endoscopes; consequently, a small amount of inferior nasal concha at that position should be removed to enable the 

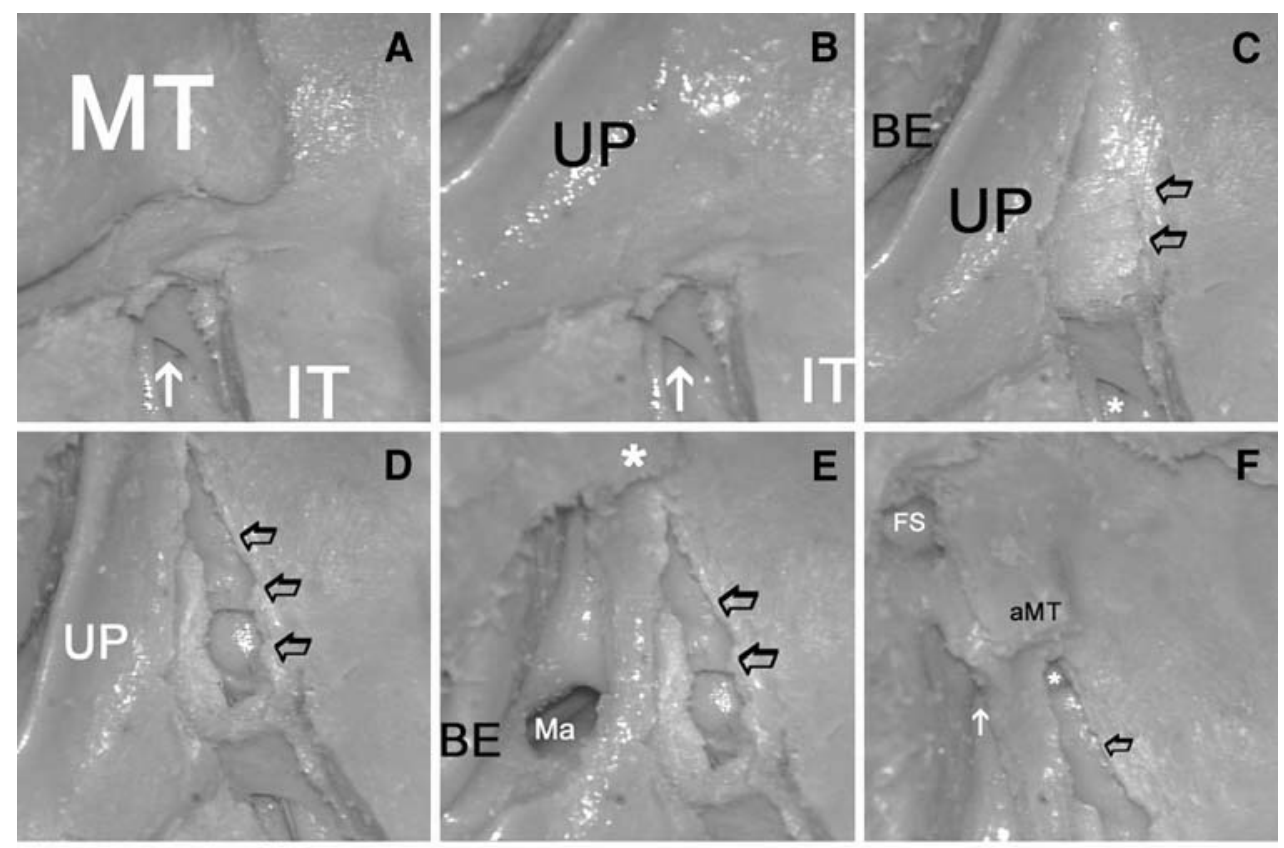

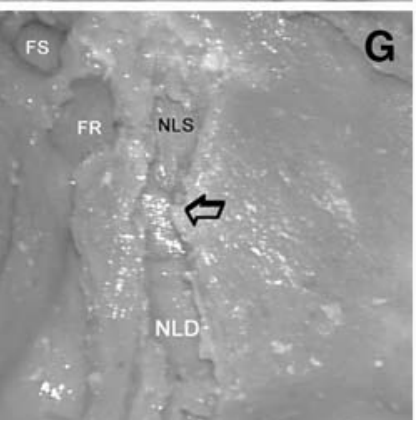

Fig. 2 a Left lateral nasal wall. A small part of the inferior turbinate (IT) was resected to see the intranasal orifice of the nasolacrimal duct (NLD, arrow). The orifice is triangular in shape. MT Middle turbinate. b Middle turbinate was resected. UP uncinate process, $I T$ inferior turbinate, arrow intranasal orifice of the nasolacrimal duct. c Resection of the mucosa covering the NLD was started, and the bone of the NLD was uncovered (arrows). UP uncinate process, BE Bulla ethmoidalis. $\mathbf{d}$ The bone over the NLD was removed and NLD was exposed (arrows). UP Uncinate process. e Uncinate process was also

surgeon to have a direct view. The intranasal orifice of the NLD was observed to be located an average of $25 \mathrm{~mm}$ from the anterior nasal spine. It was $13.7 \pm 3.15 \mathrm{~mm}$ away from the nasal floor and $14.3 \pm 2.05 \mathrm{~mm}$ distant from the anterior attachment of the inferior nasal concha. Three different types of orifice were observed: pin-point, trianguler and slitlike (Figs. 1, 2a, 3). Five pin-point (33.3\%), four triangular $(26.6 \%)$ and six slit-like (40\%) orifices were identified.

Starting from the intranasal orifice, the NLD was followed in the anterior and superior direction up to the anterior attachment of the MT (Fig. 2a-f). Anterior to the NLD there is only compact bone, without any important anatomical structure. This allows the surgeon to safely remove bone to expose the entire NLD. Posteriorly, the NLD has an intimate relationship with the uncinate process resected. Note the close relationship between the maxillary sinus antrum (Ma) and NLD (arrows). Asterisk Anterior attachment of MT. $B E$ Bulla ethmoidalis. f Superior part of the middle turbinate was resected. Frontal sinus $(F S)$ was entered. aMT Anterior attachment of the middle turbinate, white arrow frontal recess, black arrow NLD, asterisk nasolacrimal sac. $\mathbf{g}$ Bone dissection was enlarged to expose the nasolacrimal sac (NLS) more. Black arrow Transition area from NLS to the NLD. FS frontal sinus, $F R$ frontal recess

and maxillary sinus ostium (Fig. 2c-e). A transition area from NLD to the NSC was observed. The NLD was an average of $4 \mathrm{~mm}$ anterior to the MSO at the level of the anterior attachment of the MT (Fig. 2f, g). This area is located just anterior to the frontal recess area (Fig. 2f, g). Measurements of the NLD and neigbouring structures are presented in Table 1.

\section{Discussion}

The use of endoscopes in rhinology has increased the interest of surgeons to expose the nasolacrimal apparatus intranasally for surgical treatment of epiphora as an alternative to external dacryocystorhinostomy (DSR) (Metson 
Table 1 Measurements of the nasolacrimal duct
$N L D$ nasolacrimal duct, $M S O$ maxillary sinus ostium, ANS anterior nasal spine, $N F$ nasal floor, $A I T$ anterior attachment of inferior turbinate, $S D$ standard deviation

\begin{tabular}{|c|c|c|c|c|c|}
\hline Cadaver/side & $\begin{array}{l}\text { NLD } \\
\text { length (mm) }\end{array}$ & $\begin{array}{l}\text { NLD-MSO } \\
(\mathrm{mm})\end{array}$ & $\begin{array}{l}\text { NLD-ANS } \\
(\mathrm{mm})\end{array}$ & $\begin{array}{l}\text { NLD-NF } \\
(\mathrm{mm})\end{array}$ & $\begin{array}{l}\text { NLD-AIT } \\
(\mathrm{mm})\end{array}$ \\
\hline $1 \mathrm{Left}$ & 21 & 5 & 18 & 17 & 15 \\
\hline $2 \mathrm{Left}$ & 18 & 5 & 20 & 13 & 16 \\
\hline 3 Right & 24 & 3 & 31 & 7 & 18 \\
\hline 4 Right & 22 & 4 & 28 & 13 & 16 \\
\hline 5 Right & 22 & 3 & 26 & 18 & 15 \\
\hline 6 Right & 24 & 3 & 27 & 16 & 11 \\
\hline 7 Left & 25 & 3 & 27 & 16 & 11 \\
\hline 8 Left & 20 & 5 & 25 & 15 & 13 \\
\hline 9 Right & 23 & 5 & 26 & 9 & 12 \\
\hline 10 Right & 24 & 3 & 26 & 10 & 16 \\
\hline 11 Right & 20 & 3 & 21 & 12 & 13 \\
\hline $12 \mathrm{Left}$ & 23 & 4 & 27 & 17 & 16 \\
\hline $13 \mathrm{Left}$ & 19 & 4 & 20 & 13 & 14 \\
\hline 14 Right & 22 & 5 & 24 & 15 & 13 \\
\hline 15 Left & 21 & 4 & 23 & 14 & 15 \\
\hline Mean/SD & $21.9 \pm 2.03$ & $3.9 \pm 0.88$ & $24.6 \pm 3.56$ & $13.7 \pm 3.15$ & $14.3 \pm 2.05$ \\
\hline
\end{tabular}

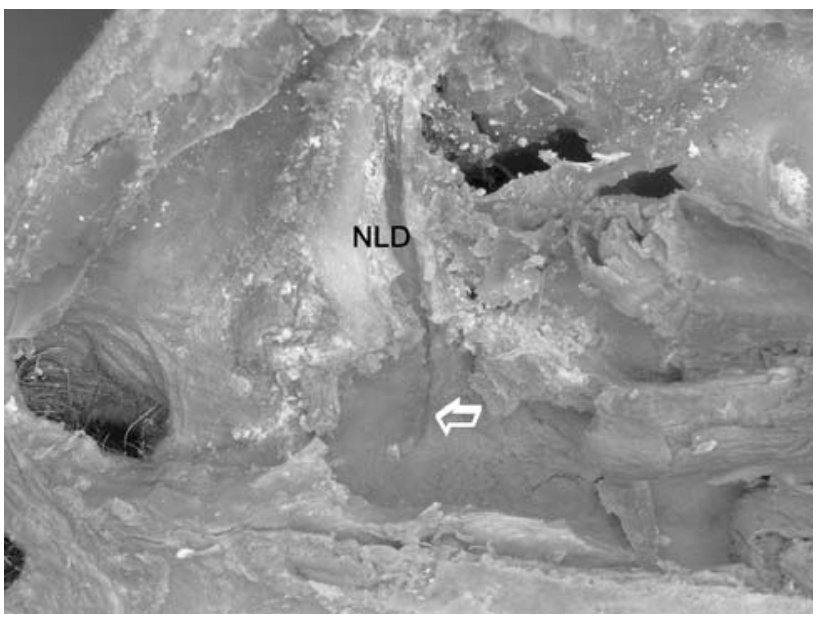

Fig. 3 Slit-like morphology of the orifice (white arrow) of nasolacrimal duct $(N L D)$. Right lateral nasal wall

1991; Weidenbecher et al. 1994; Sprekelsen and Barberan 1996; Unlu et al. 2000; Unlu et al. 2002). Successful surgical results using this approach depend on a detailed knowledge of intranasal anatomy of the NLS and NLD (McDonogh and Meiring 1989; Kurihashi et al. 1991; Rebeiz et al. 1992; Thanaviratananich et al. 1996; Groell et al. 1997; Unlu et al. 2000; Wormald et al. 2000).

Accurate knowledge of the position of the NLD on the lateral nasal wall is essential for internal endoscopic DSR (Kurihashi et al. 1991; Unlu et al. 2000, 2002). A number of landmarks can be utilized to localize the NLD on the lateral nasal wall. For example, the anterior nasal spine and anterior attachment of the inferior nasal concha can be used to estimate the position of the NLD at the beginning of endoscopic surgery. The intranasal orifice of the NLD is located approximately $25 \mathrm{~mm}$ away from the anterior nasal spine and $15 \mathrm{~mm}$ from the anterior attachment of the inferior nasal concha. The NLD passes superiorly and anteriorly from the orifice to the anterior attachment of the middle nasal concha. This course should be kept in mind during lateral osteotomies in rhinoplasty operations. Lateral osteotomy begins from the apertura pyriformis, just superior to the anterior attachment of inferior nasal concha. It follows posteriorly on the lateral nasal wall bone in which there is no obvious anatomical structure up to the NLD. Care should be taken not to violate the NLD during this procedure; it should be noted that the NLD has always been at risk during rhinoplasty operations (Unlu et al. 1996; Yigit et al. 2004).

The uncinate process and maxillary sinus ostium are also important landmarks to determine the location of the NLD. The uncinate process is attached just posterior to the NLD, which is only $4 \mathrm{~mm}$ anterior to the MSO. These intimate relationships are important during endoscopic sinus surgery. When maxillary sinus antrostomy is attempted, the uncinate process is first removed and then the maxillary sinus ostium is enlarged anteriorly using back-biting forceps. During these maneuvers, the NLD is at risk of injury due to its close relationship with the uncinate process and maxillary sinus ostium. A good familiarity with the surgical anatomical relationships is therefore important to avoid inadvertent injury during endoscopic sinus surgery. The complication of injury to the NLD following endoscopic sinus surgery has been 
reported to be $0.3-1.7 \%$ (Kennedy et al. 1987; Serdahl et al. 1990; Bolger et al. 1992; Unlu et al. 2001).

In addition, during endoscopic DSR, the mucosa on the lateral nasal wall anterior to the uncinate process should be removed in order to expose the bone covering of the NLD. We found that the mean length of the NLD is about $22 \mathrm{~mm}$, indicating that at least $2 \mathrm{~cm}$ of mucosa should be removed to expose the entire NLD. However, this amount of the mucosa removal may not be necessary for endoscopic DSR. In cases of epiphora, the sac is dilated due to obstruction in the NLD. Hence, the proximal part of the obstruction or the sac directly should be opened into the nasal cavity on the lateral nasal wall. In the majority of cases, the NLS is located above the anterior attachment of the MT (Fig. 2f, g) (Groell et al. 1997). Hence, removal of the mucosa should include the obstructed area and the proximal part of the NLD. A vertical incision, approximately $1 \mathrm{~mm}$ in length, starting from the anterior attachment of the MT in a downward direction is sufficient to expose the obstructed area (Fig. 2f, g) (Unlu et al. 2000). This is the region where the rhinostomy opening should be located. It is also important to note that this region is just anterior to the frontal recess area (Fig. $2 \mathrm{f}, \mathrm{g}$ ). This anatomical relationship should be kept in mind during bone dissection in this area in order to avoid inadvertent injury to the frontal recess. Moreover, an agger nasi cell, which is the most anteriorly placed frontal ethmoid cell and is anterior to the MT, can be encountered in this area (Calhoun et al. 1990; Wormald 2003). This might lead to confusion when searching for the NLS.

We noted three different types of NLD orifice morphology: triangular, pin-point and slit-like (Figs. 1, 2a, 3). Pin-point and slit-like openings indicate that even a very small diameter of the NLD orifice is sufficient for its patency. This observation is in agreement with the study of Lindberg et al. (1982), who found that even a very small $(1.8 \mathrm{~mm})$ ostium resulted in excellent functional outcome after an external operation.

The intranasal orifice of the NLD can also be utilized to determine the approximate position of the NLD. We found that the former is located $25 \mathrm{~mm}$ posterior to the anterior nasal spine and can be seen on the ceiling of the inferior nasal meatus. The NLD courses superiorly toward the anterior attachment of the MT. Hence, the NLD should be searched for on the line between the orifice and anterior attachment of the MT. The mean length of the NLD is about $22 \mathrm{~mm}$.

The data reported here provide some important clues for surgical orientation during endoscopic DSR. Nevertheless, further studies involving a larger series are required to accurately determine the anatomical relationship of the NLD with the frontal recess and agger nasi cells.

\section{References}

Bolger WE, Parsons DS, Mair EA et al (1992) Lacrimal drainage system injury in functional endoscopic sinus surgery. Arch Otolaryngol Head Neck Surg 118:1179-1184

Calhoun KH, Rotzler WH, Stiernberg CM (1990) Surgical anatomy of the lateral nasal wall. Otolaryngol Head Neck Surg 102(2):156160

Groell R, Schaffler GJ, Uggowitzer M, Szolar DH, Muellner K (1997) CT-anatomy of the nasolacrimal sac and duct. Surg Radiol Anat 19:189-191

Kennedy DW, Zinreich SJ, Kuhn F et al (1987) Endoscopic middle meatal antrostomy: theory, technique, and patency. Laryngoscope 97[Suppl 43]:1-9

Kurihashi K, Imada M, Yamashita A (1991) Anatomical analysis of the human lacrimal drainage pathway under operating microscope. Int Ophthal 15:411-416

Lindberg JV, Anderson RL, Bumsted RM, Barreas R (1982) Study of intranasal ostium external dacryocystorhinostomy. Arch Ophtalmol 100:1758-1762

Lucente FE, Schoenfeld PS (1990) Calibrated approach to endoscopic sinus surgery. Ann Otol Rhinol Laryngol 99(1):1-4

McDonogh M, Meiring JH (1989) Endoscopic transnasal dacryocystorhinostomy. J Laryngol Otol 103:585-587

Metson R (1991) Endoscopic surgery for lacrimal obstruction. Otolaryngol Head Neck Surg 104:473-479

Rebeiz EE, Shapshay SM, Bowlds JH, Pankratov MM (1992) Anatomic guidelines for dacryocystorhinostomy. Laryngoscope 102:1181-1184

Serdahl CL, Berris CE, Chole RA (1990) Nasolacrimal duct obstruction after endoscopic sinus surgery. Arch Ophthalmol 108(3):391-392

Sprekelsen MB, Barberan MT (1996) Endoscopic dacryocystorhinostomy: surgical technique and results. Laryngoscope 106:187-189

Thanaviratananich S, Sangsa-Ard S, Tankongchumraskul C, Chaisiwamongkol K (1996) Surgical anatomy of lateral nasal wall in Northeast Thai Cadavers. J Med Assoc Thai 79:177-184

Unlu HH, Caylan R, Kutlu N, Imamoglu M, Unal M, Yuceturk AV (1996) Active transport dacryocystography in evaluating lacrimal drainage system after rhinoplasty. Am J Rhinol 10:87-91

Unlu HH, Ozturk F, Mutlu C, Ilker SS, Tarhan S (2000) Endoscopic dacryocystorhinostomy without stents. Auris Nasus Larynx 27:65-71

Unlu HH, Goktan C, Aslan A, Tarhan S (2001) Injury to the lacrimal apparatus after endoscopic sinus surgery: surgical implications from active transport dacryocystography. Otolaryngol Head Neck Surg 124:308-312

Unlu HH, Toprak B, Aslan A, Guler C (2002) Comparison of surgical outcomes in primary endoscopic dacryocystorhimostomy with and without silicone intubation. Ann Otol Rhinol Laryngol 111:704-709

Weidenbecher M, Hosemann W, Buhr W (1994) Endoscopic endonasal dacryocystorhinostomy: results in 56 patients. Ann Otol Rhinol Laryngol 103:363-367

Wormald PJ (2003) The key to understanding the anatomy of the frontal recess. Otolaryngol Head Neck Surg 129:497-507

Wormald PJ, Kew J, Van Hasselt A (2000) Intranasal anatomy of the nasolacrimal sac in endoscopic dacryocystorhinostomy. Otolaryngol Head Neck Surg 123:307-310

Yigit O, Cinar U, Coskun BU, Akgul G, Celik D, Celebi I, Dadas B (2004) The evaluation of the effects of lateral osteotomies on the lateral drainage system after rhinoplasty using active transport dacryocystography. Rhinology 42:19-22 